\title{
Investigating Complementary and Alterna- tive Medicine Use in a Spanish-Speaking Hispanic Community in South Carolina
}

\author{
Pbilip Trangmar, MD \\ Vanessa A. Diaz, MD, MS \\ Medical University of South Carolina, \\ Department of Family Medicine, Charles- \\ ton, South Carolina
}

Conflicts of interest: none reported

\section{CORRESPONDING AUTHOR}

Vanessa A. Diaz, MD

Medical University of South Carolina 295 Calhoun St

Charleston, SC 29407

diazva@musc.edu

\begin{abstract}
PURPOSE This study investigated the use of complementary and alternative medicine (CAM) by Spanish-speaking Hispanics in the Charleston, South Carolina, area.

METHODS We administered Spanish-language questionnaires regarding use of CAM to Spanish-speaking Hispanics seeking care at either a community-based residency practice or a rural community health center.
\end{abstract}

RESULTS Overall, $69 \%$ of the 70 respondents indicated that they used some type of CAM. The most common reason for using CAM was being taught to do so by family members (33\%); other common reasons included a failure by their medical professionals to diagnose their problem (29\%), a lack of conventional medical treatment for their problem (29\%), and being unhappy with previous medical advice $(21 \%)$. The main medical conditions being treated with CAM were infections (65\%) and constipation and diarrhea (54\%), but pregnancy-related issues were also cited (27\%).

CONCLUSIONS These findings improve our understanding of alternative health care practices of Spanish-speaking Hispanics visiting primary care clinics in South Carolina. Addressing patients' reasons for CAM use may help health care professionals develop patient-centered treatment plans.

Ann Fam Med 2008;6(suppl 1):s12-s15. DOI: 10.1370/afm.736.

\section{INTRODUCTION}

omplementary and alternative medicine (CAM) encompasses
health care practices and beliefs that fall outside the conventional
systems of medicine. CAM is wide ranging and includes practices such as yoga, prayer, and acupuncture, as well as herbs, foods, and supplements. Although use of CAM is now well recognized, the reasons for this use are not always clear. In addition, often patients do not disclose their use of these therapies to their health care professionals. ${ }^{1}$ This omission is concerning because CAM may interact with prescribed medications and also because patients using CAM may have unique health care beliefs and expectations from their visit. ${ }^{2}$

Several studies have shown that the use of CAM is increasing in the United States. ${ }^{1,3}$ In particular, the prevalence of use rose from $33.8 \%$ in 1990 to $42.1 \%$ in $1997 .{ }^{3}$ This trend is seen more recently in 2002 , when the prevalence was $74.6 \%$ if prayer was included and $49.8 \%$ if prayer was excluded. ${ }^{4}$ Different studies evaluating CAM use and ethnicity have produced very different results, from a prevalence of use (not including prayer) of $77 \%$ among Hispanics in a Mexican border town $n^{5}$ to one of $27 \%$ among Hispanics participating in a national survey. ${ }^{6}$ The most common reasons for using CAM among US adults of varied ethnicities are pain $(35 \%)$ and colds $(9.5 \%){ }^{4}$

Many areas in the United States have a fairly large Hispanic popula- 
tion. There were an estimated 38 million Hispanics in the country in 2005, and the Hispanic/Latino population is expected to grow $3.9 \%$ per year until $2050 .{ }^{7}$ For that reason and because of the heterogeneity of previous findings regarding CAM use among Hispanics, we decided to evaluate CAM use in our local Hispanic population, especially because different cultural beliefs may lead to different reasons for using CAM. ${ }^{8}$

\section{METHODS}

Participants in this study were Spanish-speaking Hispanics seeking care at 2 primary care clinics with affiliations to the Family Medicine Department of the Medical University of South Carolina. One clinic is a community-based residency practice in North Charleston, South Carolina, where the Hispanic community is largely employed in construction or factory work. The other clinic is a community health center on Johns Island, South Carolina, in a rural area where agriculture is the predominant employer. A majority of Hispanics in both areas are of Mexican ancestry, although individuals of Puerto Rican and Central American ancestry are also present.

Participants were selected from all adult patients attending the 2 clinics on random days from March to December 2006 by office staff, nurses, and other clinicians based on the primary language used during the office visit specifically, if patients spoke Spanish during their visit, they were invited to participate. These patients were given a questionnaire that they completed and then returned anonymously in a sealed envelope to a box in the clinic. Respondents returning questionnaires in which they did not self-identify as Hispanic or Latino would have been excluded, but this was not necessary as all respondents identified themselves as being of these ethnicities.

Questions for this survey were adapted from previously developed and validated surveys on CAM use. ${ }^{1,3,5}$ Cognitive interviews with 5 Spanish-speaking community members were conducted to evaluate flow and understanding of the survey questions and to modify the questions accordingly.

\section{RESULTS}

A total of 70 Hispanic patients completed the questionnaire: 38 from the community-based clinic and 32 from the community health center. Their demographic characteristics are presented in Table 1.
A majority (69\%) of respondents reported using CAM. Of those who indicated their sex, $67 \%$ of women and $76 \%$ of men disclosed CAM use (Table 1). There were no significant differences in CAM use by clinic site, sex, age, education, income, or payment method in unadjusted relationships.

Herbal medicines or teas $(67 \%)$, vitamins or supplements (38\%), and foods (29\%) were the most commonly used types of CAM. Use of certain CAM items (including prayer, yoga, meditation, homeopathy, and acupuncture) was reported by only 1 person.

Although respondents used CAM for numerous health conditions, it was most frequently used for infections (reported by $65 \%$ of users) and constipation or diarrhea $(54 \%)$. It was also commonly used for high blood pressure (15\%) and diabetes (15\%). Additionally, $27 \%$ of users stated that they used CAM for pregnancy-related matters.

The leading reason given for using CAM, reported by $33 \%$ of users, was being taught to do so by family members (Table 2). A failure by medical professionals to diagnose a problem and a lack of conventional medical treatments were other common reasons given for use, each cited by $29 \%$ of users. Fully $21 \%$ of users said that they used CAM because they were unhappy with

\section{Table 1. Demographic Characteristics of Respondents and Use of CAM}

\begin{tabular}{|c|c|c|c|}
\hline Characteristic & $\begin{array}{l}\text { No. }(\%) \text { of } \\
\text { Respondents } \\
(N=70)\end{array}$ & $\begin{array}{l}\text { Percentage } \\
\text { Using CAM }\end{array}$ & $P$ Value* \\
\hline \multicolumn{4}{|l|}{ Sex } \\
\hline Female & $48(69)$ & 67 & .46 \\
\hline Male & $17(24)$ & 76 & \\
\hline No response & $5(7)$ & - & \\
\hline \multicolumn{4}{|l|}{ Age } \\
\hline$<50$ years & $53(76)$ & 71 & .49 \\
\hline$\geq 50$ years & $11(16)$ & 73 & \\
\hline No response & $6(9)$ & - & \\
\hline \multicolumn{4}{|l|}{ Education } \\
\hline Below high school & $43(61)$ & 67 & .76 \\
\hline $\begin{array}{l}\text { High school or } \\
\text { above }\end{array}$ & $19(27)$ & 74 & \\
\hline No response & $8(11)$ & - & \\
\hline \multicolumn{4}{|l|}{ Annual family income } \\
\hline$<\$ 40,000$ & $41(59)$ & 71 & .48 \\
\hline$\geq \$ 40,000$ & $7(10)$ & 85 & \\
\hline No response & $22(31)$ & - & \\
\hline \multicolumn{4}{|l|}{ Payment method } \\
\hline Insurance/Medicaid & $32(46)$ & 75 & .23 \\
\hline Self-pay & $34(49)$ & 65 & \\
\hline No response & $4(6)$ & - & \\
\hline
\end{tabular}




\begin{tabular}{|c|c|}
\hline Reason & $\begin{array}{l}\text { No. }(\%) \text { of CAM } \\
\text { Users }(n=48)\end{array}$ \\
\hline Prefer to deal with the problem myself & $3(6)$ \\
\hline $\begin{array}{l}\text { Failure of regular treatment to cure my } \\
\text { problem }\end{array}$ & $3(6)$ \\
\hline $\begin{array}{l}\text { To avoid side effects of regular medical } \\
\text { treatment }\end{array}$ & $5(10)$ \\
\hline Unhappy with advice of physicians & $10(21)$ \\
\hline $\begin{array}{l}\text { Failure of physicians to correctly diagnose } \\
\text { my problem }\end{array}$ & $14(29)$ \\
\hline There is no medical treatment for my problem & $14(29)$ \\
\hline $\begin{array}{l}\text { I have serious illness with poor chance of } \\
\text { recovery }\end{array}$ & $3(6)$ \\
\hline $\begin{array}{l}\text { This is the way I was taught to treat my } \\
\text { problem by my family }\end{array}$ & $16(33)$ \\
\hline $\begin{array}{l}\text { A friend or coworker recommended this } \\
\text { treatment to me }\end{array}$ & $4(8)$ \\
\hline I heard about this treatment in the news & $5(10)$ \\
\hline It costs less than traditional medications & $5(10)$ \\
\hline Other & $2(4)$ \\
\hline $\begin{array}{l}\text { CAM = complementary and alternative medicine. } \\
\text { Note: Users could indicate more than } 1 \text { reason. }\end{array}$ & \\
\hline
\end{tabular}

previous medical advice. Only $10 \%$ of users reported using CAM because of its lower cost relative to conventional medication.

\section{DISCUSSION}

A sizable majority of Hispanics in this study-fully $69 \%$-reported using some type of CAM. Herbal medicines and teas were the most common type used, similar to the findings of previous studies. ${ }^{4,6}$ The main reasons for use in our population were infections (ie, colds) followed by digestive ailments (ie, constipation and diarrhea). In addition, a substantial percentage of respondents seemed to be using CAM for pregnancyrelated matters, although many types of CAM have not been assessed for safety in pregnancy; this finding highlights the importance of ascertaining use of these therapies in pregnant Hispanic patients.

The leading condition for which CAM was used in this study, infections, contrasts with that of another study, wherein pain was the most common reason for use. ${ }^{4}$ The variability across studies in the percentage of Hispanics using CAM and the conditions it is used for suggests heterogeneity of use by region and ethnic background. Health care professionals throughout the United States should therefore not treat all Hispanic populations as homogeneous and should instead determine the cultural beliefs and health care practices of Hispanics within their community, possibly with questionnaires similar to the one used in this study.
Many respondents who turned to CAM did so because of what could be interpreted as a failure of the conventional medical care system to meet their needs. They were unhappy with their physicians' advice, believed that their physicians had not diagnosed their problem correctly, or thought that no conventional medical treatment existed. These negative attitudes are those of Hispanics seeking care at primary care clinics and thus having at least some experience with the health care system; therefore, some of these attitudes may be due to poor patient-clinician communication. Of note, cost was not commonly cited as a reason to use CAM, and a majority of respondents reported that the use of CAM was passed down within their family. Health care professionals thus need to be aware that CAM use may not be commonly driven by lack of access to care or finances, but instead by cultural beliefs. These needs must be addressed in order to develop culturally appropriate and effective treatment plans.

This study should be considered in light of several limitations. We do not know the number of questionnaires distributed, so we cannot calculate the response rate or assess the likelihood of response bias. Hispanic patients who did not speak Spanish were not included in the sample, limiting the generalizability of these findings to all Hispanic patients. The sample was drawn from patients willing to complete a questionnaire on CAM use when visiting primary care clinics, and not from the population at large. One can presume that respondents may have been more likely to participate if they had an interest in CAM or either were sick or had an interest in their health beyond that of the general Hispanic population. This potential bias may thus have increased the likelihood of attracting respondents who use CAM. On the other hand, the respondents' use of conventional medicine may have decreased their likelihood of using CAM. As a result, our findings are not necessarily applicable to the general Spanish-speaking Hispanic population; however, they do reflect the population of interest for this study, as we wanted to evaluate CAM use within the context of conventional medical visits. Finally, no statistically significant differences were apparent when comparing CAM use by demographic variables. None of the differences between groups exceeded $10 \%$, and thus a total sample size of more than 500 respondents would have been required to determine whether these differences were statistically significant at an $\alpha$ of .05 and power of .80. We were not able to achieve this sample size because of the study's time frame but believe that differences of about $10 \%$ may be statistically significant but not clinically meaningful.

The information from this study improves our understanding of alternative health care practices 
of Spanish-speaking Hispanics visiting primary care clinics in South Carolina. A large percentage of this population is using some form of CAM, often because of cultural beliefs or a perceived inability of the conventional medical system to meet their needs. It is therefore incumbent on health care professionals to ask Hispanic patients about CAM use and to integrate patients' beliefs and practices regarding CAM into their treatment plans.

To read or post commentaries in response to this article, see it online at http://www.annfammed.org/cgi/content/full/6/suppl_1/s12

Key words: Complementary therapies; self medication; Hispanic Americans; beliefs; customs; primary care; acceptability of health care

Submitted March 5, 2007; submitted, revised, June 20, 2007; accepted July 31, 2007.

\section{References}

1. Kuo GM, Hawley ST, Weiss LT, Balkrishnan R, Volk RJ. Factors associated with herbal use among urban multiethnic primary care patients: a cross-sectional survey. BMC Complement Altern Med. 2004;4:18.
2. Furnham A, Bhagrath R. A comparison of health beliefs and behaviours of clients of orthodox and complementary medicine. Br J Clin Psychol. 1993;32(Pt 2):237-246.

3. Eisenberg DM, Davis RB, Ettner SL, et al. Trends in alternative medicine use in the United States, 1990-1997: results of a follow-up national survey. JAMA. 1998;280(18):1569-1575.

4. Barnes PM, Powell-Griner E, McFann K, Nahin RL. Complementary and Alternative Medicine Use Among Adults: United States, 2002. Advance data from vital health and statistics, No. 343. Hyattsville, MD: National Center for Health Statistics, 2004.

5. Rivera JO, Ortiz M, Lawson ME, Verma KM. Evaluation of the use of complementary and alternative medicine in the largest United States-Mexico border city. Pharmacotherapy. 2002;22(2):256-264.

6. Graham RE, Ahn AC, Davis RB, O'Connor BB, Eisenberg DM, Phillips RS. Use of complementary and alternative medical therapies among racial and ethnic minority adults: results from the 2002 National Health Interview Survey. J Natl Med Assoc. 2005;97(4):535-545.

7. US Census Bureau, Population Division, Population Projections Branch. National population projections. 2000. http://www.census. gov/population/www/projections/natsum-T3.html. Accessed Feb 12 2007.

8. Zuckerman MJ, Guerra LG, Drossman DA, Foland JA, Gregory GG. Health-care-seeking behaviors related to bowel complaints. Hispanics versus non-Hispanic whites. Dig Dis Sci. 1996;41(1):77-82. 